Prepared in cooperation with the:

U.S. Environmental Protection Agency, Chesapeake Bay Program Office;

Maryland Department of Natural Resources; and

Virginia Department of Environmental Quality

\title{
Changes in Streamflow and Water Quality in Selected Nontidal Basins in the Chesapeake Bay Watershed,
} 1985-2004

Scientific Investigations Report 2006-5178

U.S. Department of the Interior U.S. Geological Survey

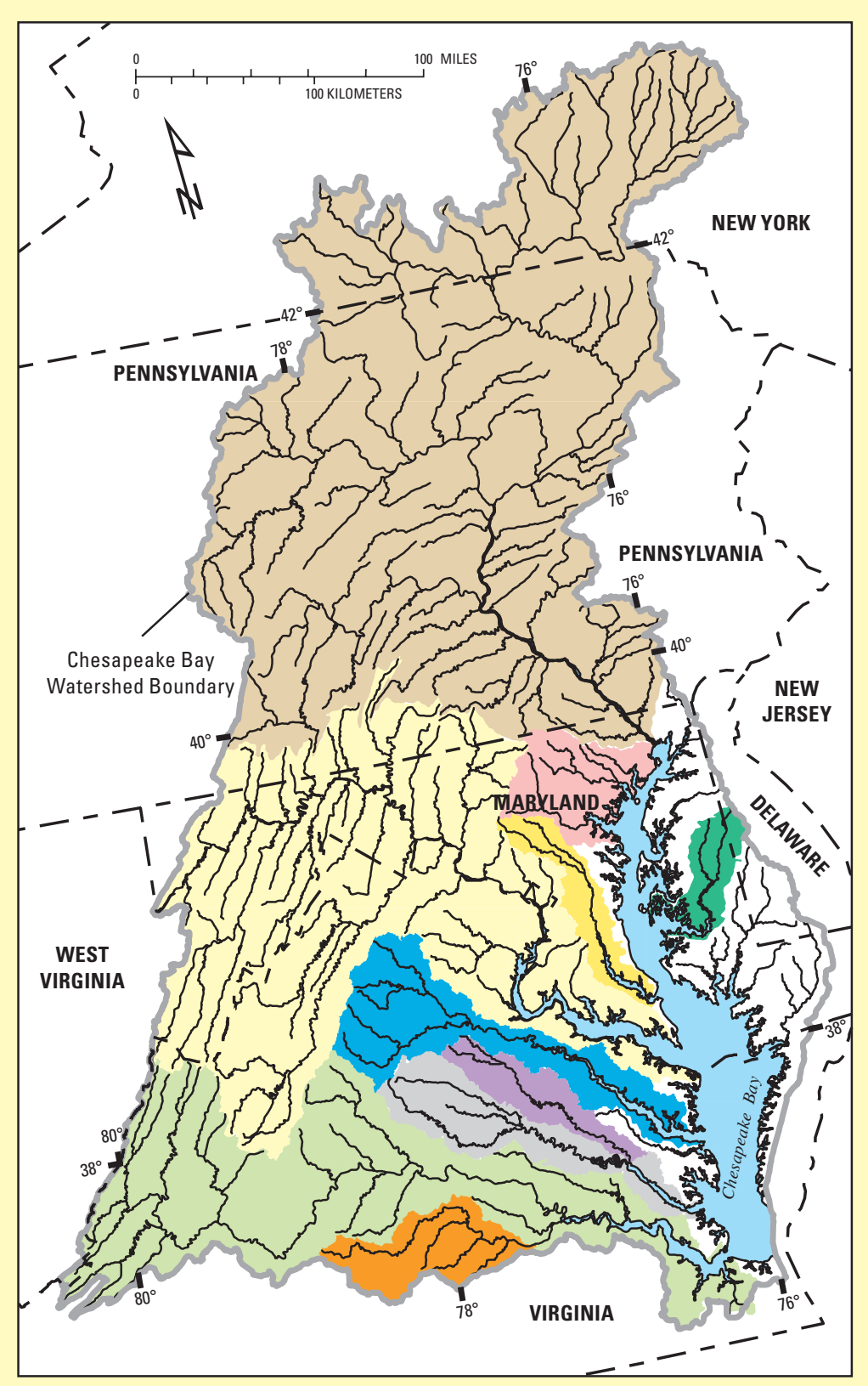


